\title{
Pijat Oksitosin dan Frekuensi Menyusui Berhubungan dengan Waktu Pengeluaran Kolostrum pada Ibu Post Sectio Caesarea di RS Kota Bandung
}

\author{
Dian Nur Hadianti' ${ }^{1}$ Rika Resmana ${ }^{1}$ \\ ${ }^{1}$ Politeknik Kesehatan Kemenkes Bandung Jurusan Kebidanan Bandung \\ Jalan Sederhana No.2, Bandung, Jawa Barat \\ Email: diannurhadianti80@gmail.com
}

\begin{abstract}
Abstrak
Kolostrum merupakan ASI pertama yang keluar mengandung banyak zat anti infeksi, sehingga bayi baru lahir yang tidak diberi kolostrum akan mudah terserang penyakit infeksi. Menurut Riskesdas 2013, bayi baru lahir yang mendapatkan ASI (kolostrum) pada waktu 24-47 jam sebesar 13\%. Hasil survei pendahuluan dari 15 ibu post SC (sectio caesarea) sebanyak 9 orang yang memberikan kolostrum pada bayinya dalam 24 jam pertama. Tujuan penelitian ini untuk mengetahui hubungan pijat oksitosin dan frekuensi menyusui dengan waktu pengeluaran kolostrum pada ibu post SC. Penelitian dilakukan dengan case control study. Sampel diambil dengan menggunakan kuota sampling sebanyak 60 responden yang terdiri dari 30 kasus ibu post SC yang kolostrumnya keluar setelah 24 jam dan 30 kontrol ibu post SC yang kolostrumnya keluar kurang dari 24 jam. Jenis data dalam penelitian ini adalah data primer. Analisis data untuk data bivariat dalam penelitian ini menggunakan uji chi-square. Hasil uji chi-square menunjukan angka $p$-value 0,001 $(p<0,05)$, dengan OR $7,00(95 \%$ Cl 3,1-15,8) artinya kolostrum yang keluar pada <satu hari setelah persalinan SC berpeluang 7,0 kali lebih besar terjadi pada ibu yang melakukan pijat oksitosin. Serta OR 15,5 (95\% Cl 3,8-63,4) artinya kolostrum yang keluar pada <satu hari setelah persalinan SC berpeluang 15,5 kali lebih besar terjadi pada ibu yang frekuensi menyusui bayinya lebih dari 7 kali dalam sehari. Kesimpulan terdapat hubungan yang signifikan antara pijat oksitosin dengan waktu pengeluaran kolostrum dan terdapat hubungan yang signifikan antara frekuensi menyusui bayi dengan waktu pengeluaran kolostrum pada ibu post SC.
\end{abstract}

Kata Kunci: pijat oksitosin, frekuensi menyusui, waktu pengeluaran kolostrum, post SC

\section{Oxytocin Massage and Breastfeeding Frequencies Associated with The Excretion Time of Colostrum in Post Partum Caesarean in Bandung City Hospital}

\begin{abstract}
Colostrum is the first breast milk that comes out which contains many substances anti-infection for the newborns, so when a newborn were not given the colostrum will be susceptible to infectious diseases. According Riskesdas 2013, newborn babies who received breast milk (colostrum) during 24-47 hours by $13 \%$. The results of a survey of 9 from 15 Post SC who give colostrum to their babies in 24 hours. The purpose of this study was to know the relationship between oxytocin massage and breastfeeding frequencies with the excretion time of colostrum in the post partum caesarean. The study methods used case-control study. The sample was selected by quota sampling of 60 respondents, consisting of 30 cases of the post SC who colostrum out after 24 hours and 30 controls the post SC who colostrum out less than 24 hours. The study used primary data with observational techniques to post SC who were treated at the hospital. The bivariant data were analyzed by chi-square test. The results showed that $p$-value $0.001(p<0.05)$, with OR 7.00 (95\% Cl 3.1-15.8) means the post SC mothers which, given oxytocin massage was 7.0 times more likely excretes colostrum on the first day after the delivery. And the OR 15.5 (95\% ci 3.8-63.4) means the colostrum that execretes on the first day after delivery was 15.5 higher in a post SC mother which
\end{abstract}


breastfeed 7 times a day. In conclusion, there was a significant relationship between oxytocin massage with excretion time and there was a significant relationship between the frequency of breastfeeding with excretion time of colostrum in the post SC.

Keywords: oxytocin massage, breastfeeding frequency, excretion time of colostrum, post SC

\section{Info Artikel:}

Artikel dikirim pada 6 September 2016

Artikel diterima pada 31 Oktober 2016

DOI : http://dx.doi.org/10.21927/jnki.2016.4(3).148-156

\section{PENDAHULUAN}

Kolostrum merupakan ASI pertama yang keluar pada ibu post partum. Kolostrum mengandung banyak zat anti infeksi sehingga apabila bayi baru lahir yang tidak diberi kolostrum akan mudah terserang penyakit infeksi (1). Pemberian kolostrum sangat dianjurkan pada bayi baru lahir.

Terdapat beberapa faktor yang dapat memengaruhi pengeluaran dan produksi kolostrum atau ASI, diantaranya dukungan psikologis, perawatan payudara, kondisi psikis ibu, frekuensi bayi menyusui, perawatan payudara, status gizi, jenis alat kontrasepsi dan jenis persalinan (2-4).

Penurunan produksi ASI juga dialami oleh ibu yang melahirkan dengan operasi sectio caesaria (SC), sehingga ibu mengalami kesulitan pada saat menyusui bayinya. Hal ini disebabkan karena penggunaan obatobatan yang digunakan pada saat operasi maupun setelah operasi. Produksi ASI dan ejeksi ASI yang sedikit pada hari-hari pertama setelah melahirkan menjadi kendala dalam pemberian ASI secara dini yang disebabkan oleh kurangnya rangsangan hormon prolaktin dan oksitosin.

Untuk mengatasi masalah menyusui pada ibu post SC, diperlukan suatu upaya yang dapat meningkatkan produksi ASI agar bayi dapat terpenuhi kebutuhan nutrisinya pada awal kehidupan. Berbagai upaya yang dapat dilakukan dalam meningkatkan produksi dan pengeluaran ASI yaitu dengan pemberian farmakologi dan non farmakologi misalnya dengan teknik akupunktur, penyinaran dengan infra merah, dan teknik pemijatan (5). Penanganan secara nonfarmakologi yang paling sederhana, praktis, dan tidak menimbulkan konflik budaya di masyarakat yaitu dengan melakukan pijat oksitosin. Pijat oksitosin merupakan usaha untuk merangsang hormon prolaktin dan oksitosin setelah melahirkan dengan cara melakukan massase atau pemijatan pada sepanjang tulang belakang (vertebrae) sampai tulang costae kelima-keenam (6).
Produksi dan pengeluaran ASI dapat dipengaruhi oleh frekuensi penyusuan bayi kepada ibunya. Otot-otot polos pada payudara berkontraksi dan pengeluaran ASI dipercepat yang disebabkan oleh sekresi oksitosin meningkat. Sekresi oksitosin meningkat disebabkan adanya isapan bayi yang akan merangsang susunan saraf di sekitarnya dan meneruskan rangsangan ini ke hipofisis anterior di otak, sehingga prolaktin disekresi dan dilanjutkan hingga ke hipofisis posterior (7). Stimulasi hormon dalam kelenjar payudara berkaitan dengan frekuensi menyusui ibu kepada bayinya. Pada periode awal setelah melahirkan, frekuensi penyusuan paling sedikit 8 kali per hari (8).

Faktor lain yang memengaruhi produksi ASI yaitu perawatan payudara, status gizi dan paritas. Penelitian Syamsinar menyatakan bahwa ada hubungan yang bermakna (signifikan) antara perawatan payudara dengan kelancaran ASI pada ibu post partum di ruang nifas Rumah Sakit TK II Pelamonia Makassar dengan nilai signifikansi lebih kecil dari 5\% ( $p=0,001$ $<\alpha=0,05)(2)$. Selain itu, menurut penelitian Nani ada hubungan yang signifikan antara status gizi ibu dengan pengeluaran kolostrum pada ibu nifas di wilayah kerja Puskesmas Patebon 01 Kabupaten Kendal dengan nilai $p$-value $=0,0 \leq 0,05$ (9). Faktor lain yang mempengaruhi produksi ASI yaitu paritas. Pengalaman yang dimiliki ibu mengenai bayi akan semakin baik apabila ibu semakin sering melahirkan sehingga ibu akan segera menyusui bayinya saat lahir, namun sebaliknya ibu akan memerlukan waktu untuk bayi dan proses menyusui itu sendiri apabila ibu baru pertama kali memiliki bayi (10). Penelitian ini bertujuan untuk untuk mengetahui hubungan pijat oksitosin dan frekuensi menyusui dengan waktu pengeluaran kolostrum pada ibu post sectio caesaria.

\section{BAHAN DAN METODE}

Jenis penelitian yang dilakukan pada penelitian ini yaitu penelitian kuantitatif dengan metode penelitian 
analitik korelasi dengan menggunakan desain rancangan case control study. Metode pengambilan sampel yang digunakan adalah quota sampling. Sampel penelitian berjumlah 60 orang, bersalin dengan tindakan SC di RS Kota Bandung, usia kehamilan aterm (36-42 minggu), bayi yang dilahirkan $\mathrm{BB}>2.500 \mathrm{gr}$, mau menyusui bayinya. Instrumen yang digunakan berupa lembar observasi. Analisis bivariat dalam penelitian ini dengan menggunakan uji statistik chi-square dengan menggunakan a sebesar 0,05.

\section{HASIL DAN BAHASAN}

\section{Distribusi Frekuensi lbu Post SC Berdasarkan Pelaksanaan Pijat Oksitosin di RS Kota Bandung}

Kegagalan dalam proses menyusui sering disebabkan karena timbulnya masalah, baik pada ibu maupun pada bayinya, salah satunya yaitu produksi ASI yang kurang. Untuk memperlancar pengeluaran produksi ASI dapat dilakukan dengan merangsang reflek oksitosin yaitu dengan pijat oksitosin (11). Distribusi frekuensi ibu post SC yang melakukan pijat oksitosin di RS Kota Bandung disajikan dalam Tabel 1.

Tabel 1. Distribusi Frekuensi lbu Post SC yang Melakukan Pijat Oksitosin di RS Kota Bandung

\begin{tabular}{lcc}
\hline \multicolumn{1}{c}{ Pijat Oksitosin } & n & $\%$ \\
\hline Pijat Oksitosin & 25 & 41,7 \\
Tidak Pijat Oksitosin & 35 & 58,3 \\
Total & 60 & 100 \\
\hline
\end{tabular}

Sumber: Data Primer Tahun 2015

Berdasarkan Tabel 1 diketahui gambaran Ibu post SC di RS Kota Bandung yang melakukan pijat oksitosin sebesar $41,7 \%$ dan yang tidak melakukan pijat oksitosin sebesar $58,3 \%$.

Pemijatan punggung dilakukan untuk menstimulasi refleks oksitosin agar membantu ibu secara psikologis, membangun kepercayaan diri ibu, sebagai upaya mengurangi nyeri atau kecemasan serta membantu ibu untuk mendapatkan pikiran positif terhadap bayinya (12). Pijatan atau rangsangan pada tulang belakang, neurotransmitter akan merangsang medulla oblongata yang langsung mengirim pesan ke hyphotalamus di hipofisis posterior untuk mengeluarkan oksitosin sehingga buah dada mengeluarkan air susunya (13).
Pijat oksitosin ini mulai efektif dari saat pengeluaran kolostrum yakni pada hari- hari pertama pasca melahirkan (14). Durasi pijat oksitosin ini dapat dilakukan selama 2-3 menit tiap sesi dan dalam satu kali sesi pemijatan dapat diulang hingga 3 kali (15). Pijat ini di Srilanka dapat dilakukan dalam beberapa menit (12).

Produksi ASI dipengaruhi oleh hormon prolaktin sedangkan pengeluaran dipengaruhi oleh hormon oksitosin. Pijatan pada tulang belakang menyebabkan hormon oksitosin keluar dan ASI pun cepat keluar, sehingga ibu merasa tenang, rileks, meningkatkan ambang rasa nyeri dan mencintai bayinya (13).

Pijat oksitosin berpengaruh kepada pengeluaran ASI. Hal ini sesuai dengan penelitian Wulandari, bahwa ada pengaruh pijat oksitosin terhadap rerata waktu pengeluaran kolostrum (5,21 jam) (16). Selain itu, penelitian Ummah, menyebutkan bahwa rata-rata ibu pascasalin normal yang diberikan pijat oksitosin lebih cepat mengeluarkan ASI (6,21 jam) daripada yang tidak diberikan pijat oksitosin (8,93 jam) (17).

\section{Distribusi Frekuensi lbu Post SC Berdasarkan Frekuensi Menyusui di RS Kota Bandung}

Berikut penyajian frekuensi menyusui bayi yang dilakukan ibu post SC yang disajikan dalam Tabel 2.

\section{Tabel 2. Distribusi Frekuensi lbu Post SC Berdasarkan Frekuensi Menyusui bayi di RS Kota Bandung}

\begin{tabular}{lcc}
\hline \multicolumn{1}{c}{ Frekuensi Menyusui } & $\mathbf{n}$ & $\%$ \\
\hline$\geq 7$ kali sehari & 38 & 63,3 \\
$<7$ kali sehari & 22 & 36,7 \\
Total & 60 & 100 \\
\hline
\end{tabular}

Sumber: Data Primer Tahun 2015

Berdasarkan Tabel 2, bahwa gambaran Ibu post SC di RS Kota Bandung yang menyusi bayi $\geq 7$ kali sehari sebesar $63,3 \%$ dan yang menyusui bayi $<7$ kali sehari sebesar 22\%.

Produksi ASI dipengaruhi frekuensi menyusui. Menyusui yang baik sesuai dengan kebutuhan bayi karena bayi akan menentukan sendiri kebutuhannya, sehingga sebaiknya menyusui tanpa dijadwal (on demand). Menyusui dengan cara on demand akan mencegah timbulnya masalah menyusui. Selain itu isapan bayi akan merangsang produksi ASI selanjutnya (18). 
Pada 2 hari pertama setelah lahir, beberapa bayi tidur selama 6-8 jam sehingga ASI diberikan setiap 4 jam, dan yang paling baik adalah membangunkannya selama siklus tidurnya. Pada hari ketiga, sebagian besar bayi menyusu setiap 2-3 jam. Bayi yang sehat dapat mengosongkan satu payudara sekitar 5-7 menit. Menyusui bayi dianjurkan secara non-jadwal (on demand) karena bayi akan menentukan sendiri kebutuhannya, isapan bayi sangat berpengaruh pada rangsangan produksi ASI selanjutnya (4).

Menurut Lusa dalam Amahorseja, bahwa frekuensi penyusuan berkaitan dengan kemampuan stimulasi hormon dalam kelenjar payudara. Semakin sering bayi menyusu pada payudara ibu, maka produksi dan pengeluaran ASI akan semakin banyak. Penelitian Amahorseja yang menyatakan bahwa ada pengaruh yang signifikan antara frekuensi penyusuan terhadap kelangsungan produksi ASI $(p=0,000)$ (19).

\section{Distribusi Frekuensi lbu Post SC Berdasarkan Perawatan Payudara di RS Kota Bandung}

Berikut penyajian perawatan payudara yang dilakukan ibu post SC yang disajikan dalam Tabel 3.

Tabel 3. Distribusi Frekuensi Ibu Post SC Berdasarkan Perawatan Payudara di RS Kota Bandung

\begin{tabular}{lcc}
\hline \multicolumn{1}{c}{ Perawatan payudara } & n & $\%$ \\
\hline Perawatan & 42 & 70,0 \\
Tidak Perawatan & 18 & 30,0 \\
Total & 60 & 100 \\
\hline
\end{tabular}

Sumber: Data Primer Tahun 2015

Berdasarkan Tabel3, diketahui bahwagambaran ibu post SC di RS Kota Bandung yang melakukan perawatan payudara sebesar $70 \%$ dan yang tidak melakukan perawatan payudara sebesar $30 \%$.

Ibu hamil yang menjelang masa laktasi atau selama enam minggu terakhir masa kehamilan, perlu melakukan perawatan fisik payudara dengan cara mengurut payudara untuk menghindari penyumbatan duktus laktiferus dan melancarkan ASI (3).

Faktor yang sangat berpengaruh terhadap pengeluaran kolostrum adalah faktor fisik dan psikologis ibu. Persalinan secara spontan dan persalinan SC dapat mempengaruhi kondisi fisik ibu, termasuk dapat mempengaruhi pengeluaran kolostrum. Perbedaan lama waktu yang cukup besar pada saat pengeluaran kolostrum menunjukkan pengaruh persalinan SC terhadap keluarnya kolostrum (20).

\section{Distribusi Frekuensi lbu Post SC Berdasarkan Status Gizi di RS Kota Bandung}

Distribusi frekuensi ibu post SC berdasarkan status gizi ibu disajikan dalam Tabel 4.

Tabel 4. Distribusi Frekuensi lbu Post SC

Berdasarkan Status Gizi di RS Kota Bandung

\begin{tabular}{lcc}
\hline \multicolumn{1}{c}{ Status Gizi } & $\mathbf{n}$ & $\%$ \\
\hline Baik & 47 & 78,3 \\
Kurang & 13 & 21,7 \\
Total & 60 & 100 \\
\hline
\end{tabular}

Sumber: Data Primer Tahun 2015

Berdasarkan Tabel 4, diketahui gambaran ibu post SC di RS Kota Bandung dengan status gizi baik sebesar $78,3 \%$ dan status gizi kurang sebesar $21,7 \%$

Produksi ASI sangat dipengaruhi oleh makanan yang di makan ibu, apabila ibu makan secara teratur dan cukup mengandung gizi yang diperlukan akan dapat memengaruhi produksi ASI, karena kelenjar pembuat ASI tidak dapat bekerja dengan sempurna tanpa makanan yang cukup (21).

Ibu akan merasakan bahwa ASI yang dikeluarkan hanya sedikit apabila kemampuan tubuh dalam memproduksi ASI kurang. Hal ini disebabkan status gizi ibu kurang, kenaikan berat badan ibu kurang dari rekomendasi Institute of Medicine (IOM), cadangan lemak ibu untuk menyusui rendah, karena cadangan lemak ibu yang disimpan selama hamil digunakan untuk memproduksi ASI (22).

\section{Distribusi Frekuensi lbu Post SC Berdasarkan Paritas di RS Kota Bandung}

Distribusi frekuensi ibu post SC berdasarkan paritas ibu post SC disajikan dalam Tabel $\mathbf{5}$.

Tabel 5. Distribusi Frekuensi lbu Post SC Berdasarkan Paritas di RS kota Bandung

\begin{tabular}{lcc}
\hline \multicolumn{1}{c}{ Paritas } & $\mathbf{n}$ & $\%$ \\
\hline Multipara & 39 & 65,0 \\
Primipara & 21 & 35 \\
Total & 60 & 100 \\
\hline
\end{tabular}

Sumber: Data Primer Tahun 2015 
Berdasarkan Tabel 5, diketahui bahwa gambaran ibu post SC di RS Kota Bandung dengan multipara sebesar $65 \%$ dan primipara sebesar $21 \%$. Ibu yang sering melahirkan akan segera menyusui bayinya karena sudah memiliki pengalaman mengenai bayi, sedangkan ibu yang baru pertama kali melahirkan memerlukan waktu untuk menyusui bayinya (10).

\section{Hubungan Pijat Oksitosin terhadap Waktu Pengeluaran Kolostrum pada lbu Post SC}

Hubungan pijat oksitosin terhadap waktu pengeluaran kolostrum pada ibu post $S C$ disajikan dalam Tabel 6. Tabel tersebut menunjukkan bahwa kelompokibu post SC yang kolostrumnya keluar kurang dari satu hari $83,3 \%$ terjadi pada ibu yang melakukan pijatoksitosin. Sebaliknya pada kelompok ibu yang kolostrumnya keluar lebih dari satu hari seluruhnya tidak melakukan pijat oksitosin.

Hasil uji statistik menunjukkan nilai $\mathrm{p}=0,001$, berarti pada alpha $5 \%$ terdapat hubungan antara pijat oksitosin dengan waktu pengeluaran kolostrum pada ibu post SC. Hasil OR 7,00 (95\% Cl 3,1-15,8) artinya kolostrum yang keluar pada hari pertama setelah persalinan berpeluang 7 kali lebih besar terjadi pada ibu post SC yang melakukan pijat oksitosin.

Pijat oksitosin merupakan salah satu solusi untuk mengatasi ketidaklancaran produksi ASI. Pijat oksitosin dilakukan sepanjang tulang belakang (vertebrae) sampai tulang costae kelima-keenam dan merupakan usaha untuk merangsang hormon prolaktin dan oksitosin setelah melahirkan serta akan membuat rasa nyaman dan rileks pada ibu sesudah mengalami persalinan dengan sectio caesarea dan rasa nyaman tersebut merangsang pengeluaran hormon oksitosin untuk memproduksi ASI (6). Pijat oksitosin berpengaruh kepada pengeluaran ASI.

Pada penelitian ini pijat oksitosin diberikan pada kelompok ibu menyusui post SC di RS Kota Bandung. Hasilnya menunjukkan bahwakolostrum yang keluar pada hari pertama setelah persalinan berpeluang 7.0 kali lebih besar terjadi pada ibu post SC yang melakukan pijat oksitosin.

Hal ini sesuai dengan penelitian Mardiyaningsih, yang menyebutkan bahwa ibu post SC yang diberikan intervensi kombinasi teknik mamet dan pijat oksitosin berpeluang 11,5 kali lebih besar untuk mempunyai produksi ASI lancar dibandingkan dengan kelompok kontrol (23). Selain itu, penelitian Rusdiarti menunjukkan bahwa rata-rata pengeluaran ASI pada ibu nifas yang tidak dilakukan pijat oksitosin sebesar 4,61 hari sedangkan rata-rata pengeluaran ASI pada ibu nifas yang dilakukan pijat oksitosin di Kabupaten Jember tahun 2014 sebesar 11,78 menit (24).

\section{Hubungan Frekuensi Menyusui Bayi dengan Waktu Pengeluaran Kolostrum pada lbu Post SC}

Hubungan frekuensi menyusui bayi dengan waktu pengeluaran kolostrum pada ibu post SC disajikan dalam Tabel 7.

Tabel 6. Penerapan Pijat Oksitosin terhadap Waktu Pengeluaran Kolostrum pada ibu Post SC di RS Kota Bandung

\begin{tabular}{lcccccc}
\hline \multicolumn{1}{c}{ Kategori } & \multicolumn{3}{c}{ Waktu Keluarnya Kolostrum } & & OR \\
& \multicolumn{2}{c}{ < Satu Hari } & \multicolumn{2}{c}{$>$ Satu Hari } & $\boldsymbol{p}$-value & (95\% Cl) \\
& $\mathbf{n}$ & $\%$ & $\mathbf{n}$ & $\%$ & & \\
\hline Pijat Oksitosin & 25 & 83,3 & 0 & 0 & 0,001 & 7,00 \\
Tidak Pijat Oksitosin & 5 & 16,7 & 30 & 100 & & $(3,1-15,8)$ \\
Total & 30 & 100 & 30 & 100 & & \\
\hline
\end{tabular}

Sumber: Data Primer Tahun 2015

Tabel 7. Frekuensi Menyusui terhadap Waktu Pengeluaran Kolostrum pada ibu Post SC di RS Kota Bandung

\begin{tabular}{|c|c|c|c|c|c|c|}
\hline \multirow{3}{*}{$\begin{array}{l}\text { Kategori Frekuensi Menyusui Bayi } \\
\text { dalam Sehari }\end{array}$} & \multicolumn{4}{|c|}{ Waktu Keluarnya Kolostrum } & \multirow{3}{*}{$p$-value } & \multirow{3}{*}{$\begin{array}{c}\text { OR } \\
(95 \% \mathrm{Cl})\end{array}$} \\
\hline & \multicolumn{2}{|c|}{$<$ Satu Hari } & \multicolumn{2}{|c|}{ >Satu Hari } & & \\
\hline & $\mathbf{n}$ & $\%$ & $\mathbf{n}$ & $\%$ & & \\
\hline$\geq 7$ kali sehari & 27 & 90 & 11 & 36,7 & \multirow{3}{*}{0,001} & \multirow{3}{*}{$\begin{array}{c}15,5 \\
(3,8-63,4)\end{array}$} \\
\hline$<7$ kali sehari & 3 & 10 & 19 & 63,3 & & \\
\hline Total & 30 & 100 & 30 & 100 & & \\
\hline
\end{tabular}

Sumber: Data Primer Tahun 2015 
Tabel 7 menunjukkan bahwa kelompok ibu post SC yang kolostrumnya keluar kurang dari satu hari $90,0 \%$ terjadi pada ibu yang frekuensi menyusui bayinya lebih dari 7 kali dalam sehari. Sebaliknya untuk kelompok ibu yang kolostrumnya keluar lebih dari satu hari $63,3 \%$ terjadi pada ibu yang frekuensi menyusui bayinya kurang dari 7 kali dalam sehari. Hasil uji statistik menunjukkan nilai $\mathrm{p}=0,001$, berarti pada alpha $5 \%$ terdapat hubungan antara frekuensi menyusui bayi dengan waktu pengeluaran kolostrum pada ibu post SC. Hasil OR 15,5 (95\% Cl 3,8-63,4) artinya kolostrum yang keluar pada hari pertama setelah persalinan berpeluang 15,5 kali lebih besar terjadi pada ibu post SC yang frekuensi menyusui bayinya lebih dari 7 kali dalam sehari.

Frekuensi ibu menyusui bayinya sangat berpengaruh pada produksi dan pengeluaran ASI. Produksi dan pengeluaran ASI dapat dipengaruhi oleh frekuensi penyusuan bayi kepada ibunya. Otot-otot polos pada payudara berkontraksi dan pengeluaran ASI dipercepat yang disebabkan oleh sekresi oksitosin meningkat. Sekresi oksitosin meningkat disebabkan adanya isapan bayi yang akan merangsang susunan saraf di sekitarnya dan meneruskan rangsangan ini ke hipofisis anterior di otak, sehingga prolaktin disekresi dan dilanjutkan hingga ke hipofisis posterior (7). Stimulasi hormon dalam kelenjar payudara berkaitan dengan frekuensi menyusui ibu kepada bayinya. Pada periode awal setelah melahirkan, frekuensi penyusuan paling sedikit 8 kali per hari (8). Pada 2 hari pertama setelah lahir, ASI diberikan setiap 4 jam, dan yang paling baik adalah membangunkannya selama siklus tidurnya. Pada hari ketiga, sebagian besar bayi menyusu setiap 2-3 jam (4).

Berdasarkan penelitian Haryani bahwa faktorfaktor yang memengaruhi proses laktasi yaitu kondisi payudara dan perawatannya $(47 \%)$, teknik menyusui (55\%), posisi menyusui (57\%), frekuensi dan durasi menyusui $(57 \%)(25)$.

Hasil survei yang dilakukan Sourila et al di Rumah Sakit Peloponnese Yunani, bahwa frekuensi menyusui ibu post partum cukup tinggi $91,5 \%$, adapun faktor yang memengaruhi proses menyusui yaitu $34 \%$ mengalami kesulitan menyusui (produksi ASI kurang, lecet puting susu), faktor ekonomi (50\%) dan tingkat pendidikan (30\%) (26).

\section{Hubungan Perawatan Payudara Selama Hamil dengan Waktu Pengeluaran Kolostrum pada lbu Post SC}

Hubungan perawatan payudara dengan waktu pengeluaran kolostrum pada ibu post SC disajikan dalam Tabel 8.

Tabel 8. Perawatan Payudara terhadap Waktu Pengeluaran Kolostrum pada lbu Post SC di RS Kota Bandung

\begin{tabular}{|c|c|c|c|c|c|c|}
\hline \multirow{3}{*}{ Kategori } & \multicolumn{4}{|c|}{ Waktu Keluarnya Kolostrum } & \multirow{3}{*}{$p$-value } & \multirow{3}{*}{$\begin{array}{c}\text { OR } \\
(95 \% \mathrm{Cl})\end{array}$} \\
\hline & \multicolumn{2}{|c|}{$<$ Satu Hari } & \multicolumn{2}{|c|}{ >Satu Hari } & & \\
\hline & $\mathbf{n}$ & $\%$ & $\mathbf{n}$ & $\%$ & & \\
\hline Perawatan Payudara & 23 & 76,7 & 19 & 63,3 & & \\
\hline Tidak Perawatan Payudara & 7 & 23,3 & 11 & 36,7 & 0,398 & $(0,6-5,8)$ \\
\hline Total & 30 & 100 & 30 & 100 & & \\
\hline
\end{tabular}

Sumber: Data Primer Tahun 2015

Tabel 8 menunjukkan bahwa kelompok ibu post SC yang kolostrumnya keluar kurang dari satu hari $76,7 \%$ terjadi pada ibu yang melakukan perawatan payudara, begitupun untuk kelompok ibu yang kolostrumnya keluar lebih dari satu hari $63,3 \%$ terjadi pada ibu yang melakukan perawatan payudara. Hasil uji statistik menunjukkan nilai $p=0,398$, berarti pada alpha 5\% tidak terdapat hubungan antara perawatan payudara dengan waktu pengeluaran kolostrum pada ibu post SC.

Penelitian Syamsinar, menyatakan bahwa ada hubungan yang bermakna (signifikan) antara perawatan payudara dengan kelancaran ASI pada ibu post partum di ruang nifas Rumah Sakit TK.II Pelamonia Makassar dengan nilai signifikansi lebih kecil dari 5\% $(p=0,001<\alpha=0,05)(2)$. Terdapat responden yang melakukan perawatan payudara, tetapi kelancaran pengeluaran ASI nya tidak lancar. Masalah saat menyusui seperti ASI tidak keluar dan puting susu tidak menonjol akan terjadi apabila perawatan payudara tidak dilakukan saat hamil tetapi hanya dilakukan saat pasca persalinan. Perawatan payudara yang baik dilakukan berkesinambungan mulai saat kehamilan hingga pasca persalinan (13). 
Penelitian lain yang dilakukan oleh Haryani yang menyatakan bahwa perawatan payudara masa antenatal berhubungan dengan kecepatan sekresi ASI postpartum primipara dengan menunjukkan nilai $p=0,001$ (14). Perbedaan hasil penelitian tersebut kemungkinan dapat disebabkan oleh terhentinya keberlangsungan perawatan payudara ketika menjelang dan setelah persalinan, dengan alasan ibu mendapatkan tindakan SC yang mengakibatkan ibu mengalami ketidaknyamanan dan nyeri pada luka bekas SC.

Faktor yang sangat berpengaruh terhadap pengeluaran kolostrum adalah faktor fisik dan psikologis ibu. Persalinan secara spontan dan persalinan SC dapat memengaruhi kondisi fisik ibu, termasuk dapat memengaruhi pengeluaran kolostrum. Perbedaan lama waktu yang cukup besar pada saat pengeluaran kolostrum menunjukkan pengaruh persalinan SC terhadap keluarnya kolostrum (15).

Persalinan secara spontan dapat memengaruhi rata-rata keluarnya kolostrum pertama yaitu lebih cepat 23,96 jam (hampir 1 hari) dibandingkan responden dengan persalinan SC, yaitu persalinan spontan adalah 10,77 jam (kurang dari 1 hari) sedangkan responden persalinan SC sebesar 34,73 jam (2 hari) (16).

\section{Hubungan Status Gizi lbu Selama Hamil dengan Waktu Pengeluaran Kolostrum pada lbu Post SC}

Status Gizi lbu selama hamil dengan waktu pengeluaran kolostrum pada ibu post SC disajikan dalam Tabel 9.
Tabel 9 menunjukkan bahwa kelompok ibu post SC yang kolostrumnya keluar kurang dari satu hari 90,0\% terjadi pada ibu yang status gizi selama hamilnya baik, begitupun untuk kelompok ibu yang kolostrumnya keluar lebih dari satu hari $66,7 \%$ terjadi pada ibu yang status gizi selama hamilnya kurang. Hasil uji statistik menunjukkan nilai $p=0,06$, berarti pada alpha $5 \%$ tidak terdapat hubungan antara status gizi ibu selama hamil dengan waktu pengeluaran kolostrum pada ibu post SC.

Status gizi selama kehamilan merupakan hal yang sangat berpengaruh terhadap kesehatan ibu dan janin. Selama proses kehamilan metabolisme energi akan meningkat. Hal ini disebabkan selama dalam kehamilan terjadi proses pertumbuhan bayi, dan proses penyesuaian fisiologis dan metabolisme. Berat badan seorang ibu hamil dapat bertambah sekitar $11-13 \mathrm{~kg}(9)$.

Keterlambatan onset laktasi pada ibu juga bisa disebabkan faktor IMT. Ibu post partum dengan IMT normal (>18,5-25) sebagian besar terjadi onset laktasi cepat dan ibu post partum dengan IMT yang overweight sebagian terjadi keterlambatan onset laktasi. IMT ibu yang normal terjadi onset laktasi yang cepat disebabkan ibu yang memiliki IMT normal memiliki kadar progesteron yang lebih rendah dibandingkan dengan ibu yang memiliki IMT overweight (18).

Penelitian ini menunjukkan bahwa tidak terdapat hubungan antara status gizi ibu selama hamil dengan waktu pengeluaran kolostrum pada ibu post SC. Hal ini berbeda dengan penelitian Nani yang menyatakan bahwa ada hubungan yang signifikan antara status

Tabel 9. Status Gizi Ibu terhadap Waktu Pengeluaran Kolostrum pada Ibu Post SC di RS Kota Bandung

\begin{tabular}{|c|c|c|c|c|c|c|}
\hline \multirow{3}{*}{$\begin{array}{l}\text { Kategori } \\
\text { Status Gizi }\end{array}$} & \multicolumn{4}{|c|}{ Waktu Keluarnya Kolostrum } & \multirow{3}{*}{$p$-value } & \multirow{3}{*}{$\begin{array}{c}\text { OR } \\
(95 \% \mathrm{Cl})\end{array}$} \\
\hline & \multicolumn{2}{|c|}{$<$ Satu Hari } & \multicolumn{2}{|c|}{ >Satu Hari } & & \\
\hline & $\mathbf{n}$ & $\%$ & $\mathbf{n}$ & $\%$ & & \\
\hline Baik & 27 & 90 & 20 & 66,7 & \multirow[t]{3}{*}{0,06} & \multirow{3}{*}{$\begin{array}{c}4,500 \\
(1,09-18,5)\end{array}$} \\
\hline Kurang & 3 & 10 & 10 & 33,3 & & \\
\hline Total & 30 & 100 & 30 & 100 & & \\
\hline
\end{tabular}

Sumber: Data Primer Tahun 2015

gizi ibu dengan pengeluaran kolostrum pada ibu nifas di wilayah kerja Puskesmas Patebon 01 Kabupaten Kendal dengan nilai $p$-value: $0,0 \leq 0,05$ (9).

Hal yang menyebabkan perbedaan dari hasil penelitian ini kemungkinan disebabkan karena kondisi ibu yang melahirkan dengan proses SC sehingga membuat ibu merasa tidak nyaman dan stres yang dapat mempengaruhi waktu pengeluaran kolostrum .
Selain itu, status gizi ibu bukan hanya dinilai selama hamil, namun hal yang penting adalah dengan memperhatikan asupan gizi ibu selama hamil, saat melahirkan dan saat nifas.

Pengeluaran ASI pada ibu post partum normal berbeda dengan ibu post sectio caesarea yang samasama dilakukan IMD. Ibu yang melahirkan normal 
Tabel 10. Jumlah Paritas terhadap Waktu Pengeluaran Kolostrum pada Ibu Post SC di RS Kota Bandung

\begin{tabular}{|c|c|c|c|c|c|c|}
\hline \multirow{3}{*}{$\begin{array}{c}\text { Kategori } \\
\text { Jumlah Paritas }\end{array}$} & \multicolumn{4}{|c|}{ Waktu Keluarnya Kolostrum } & \multirow{3}{*}{$p$-value } & \multirow{3}{*}{$\begin{array}{c}\text { OR } \\
(95 \% \mathrm{Cl})\end{array}$} \\
\hline & \multicolumn{2}{|c|}{ <Satu Hari } & \multicolumn{2}{|c|}{ >Satu Hari } & & \\
\hline & $\mathbf{n}$ & $\%$ & $\mathbf{n}$ & $\%$ & & \\
\hline Multipara & 19 & 63,3 & & & & \\
\hline Primipara & 11 & 36,7 & 10 & 33,3 & 1,00 & $\begin{array}{c}0,864 \\
(0,2)\end{array}$ \\
\hline Total & 30 & 100 & 30 & 100 & & \\
\hline
\end{tabular}

Sumber: Data Primer Tahun 2015

pengeluaran ASI lebih cepat, karena selam persalinan ibu tetap dianjurkan makan dan minum. Berbeda dengan ibu post sectio caesarea, adanya pengaruh anestesi serta masih banyak pandangan pasien yang tidak memperbolehkan atau mengurangi makan dan minum setelah operasi. Faktor utama pada post sectio caesarea, karena mengalami nyeri luka, yang mengganggu kenyamanan ibu dan mengakibatkan pengeluaran endorfin lambat sehingga aliran darah tidak lancar ke otak. Hipotalamus lambat menerima sinyal yang akan ditransfer ke hipofisis posterioryang mengeluarkan oksitosin dalam merangsang refleks aliran ASI (15).

\section{Hubungan Jumlah Paritas dengan Waktu Pengeluaran Kolostrum pada lbu Post SC}

Berikut hubungan jumlah paritas dengan waktu pengeluran kolostrum pada ibu post SC yang disajikan dalam Tabel 10. Hasil dari tabel tersebut menunjukkan bahwa kelompok ibu post SC yang kolostrumnya keluar kurang dari satu hari $63,3 \%$ terjadi pada ibu yang multipara, untuk kelompok ibu yang kolostrumnya keluar lebih dari satu hari $66,7 \%$ terjadi pada ibu yang primipara. Hasil dari uji statistik menunjukkan nilai $p=1,00$, berarti pada alpha $5 \%$ tidak terdapathubungan antara paritas (jumlah anak) dengan waktu pengeluaran kolostrum pada ibu post SC.

Ibu multipara memiliki produksi ASI lebih rendah dari primipara pada kelompok ibu yang tidak rooming in dan diberikan jadwal menyusui 7x sehari, sedangkan pada ibu dan bayi dengan rooming in tidak ada perbedaan dalam pengeluaran ASI (23). Hasil penelitian ini berbeda dengan pendapat dan hasil penelitian lain, karena banyak faktor lain yang lebih berpengaruh terhadap waktu dan pengeluaran kolostrum.

Hasil penelitian Nasihah menyatakan bahwa sebanyak 17 orang (56\%) dari responden merupakan ibu primipara yang sebagian besar tidak memberikan kolostrum, sedangkan sebagian kecil atau sebanyak
7 ibu grande multipara (21\%) memberikan kolostrum (27).

\section{SIMPULAN DAN SARAN}

Berdasarkan hasil dan bahasan didapatkan simpulan terdapat hubungan antara pijat oksitosin dengan waktu pengeluaran kolostrum pada post SC. Terdapat hubungan antara frekuensi menyusui dengan waktu pengeluaran kolostrum pada post SC.

Saran ditujukan kepada seluruh pelayanan kesehatan khususnya bidan yang memberikan asuhan terhadap ibu post partum, untuk dapat meningkatkan kualitas asuhan selama nifas di antaranya dengan memberikan beberapa informasi melalui konseling mengenai faktor-faktor yang dapat memengaruhi waktu pengeluaran kolostrum khususnya mempelajari mengenai cara melakukan pijat oksitosin dan dapat dijadikan sebagai standar pelayanan terhadap ibu post partum.

\section{RUJUKAN}

1. Suharyono. Diare Akut, Klinik dan Laboratorik. Jakarta: PT. Rineka Cipta; 2001.

2. Syamsiar, Dode S, Ferrial E. Faktor-Faktor yang Berhubungan dengan Kelancaran Pengeluaran ASI pada Ibu Post Partum di Ruang Nifas Rumah Sakit TK.II Pelamonia Makassar. J IIm Kesehat Diagnosis. 2013;2(5):6.

3. Siregar A. Pemberian ASI Eksklusif dan FaktorFaktor yang Mempengaruhinya. Medan. FKM Universitas Sumatera Utara [Internet]. 2004 [cited 2016 Jul 2]. Available from: http://repository.usu. ac.id/bitstream/123456789/32726/1/fkm-arifin4.pdf.

4. Rahayu DP, Mahanani SN. Faktor-faktor yang Mempengaruhi Produksi ASI pada Ibu Nifas di RS Baptis Kediri. STIKES RS Baptis Kediri; 2012.

5. Patel U, Gedam DS. Effect of back Massage on Lactation among Postnatal Mothers. Int J Med Res Rev. 2013;1(1):5-11. 
6. Purnama RRW. Efektivitas antara Pijat Oksitosin dan Breastcare Terhadap Produksi Asi pada Ibu Post Partum dengan Sectio Caesarea di RSUD Banyumas. FK UNSOED; 2013.

7. Bobak. Buku Ajar Keperawatan Maternitas. Jakarta: EGC; 2015.

8. Gustriani N. Pengaruh Pijat Oksitosin terhadap Pengeluaran ASI pada Pasien Post Seksio Sesarea di Ruangan Nifas Rumah Sakit Wilayah Makassar. Universitas Hasanuddin Makassar; 2015.

9. Nani SA, Masruroh. Hubungan Status Gizi Ibu dengan Pengeluaran Kolostrum pada lbu Nifas di Wilayah Puskesmas Patebon 01 Kabupaten Kendal. J IImu Kesehat. 2016;6(1):1-6.

10. Manuaba. Buku Pengantar Kuliah Obstetri. Jakarta: EGC; 2007.

11. Lestari A, Zuhana N, Prasojo S. Gambaran Pengetahuan Bidan Mengenai Pijat Oksitosin di RSUD Kraton Kabupaten Pekalongan Tahun 2013. STIKES Muhammadiyah Pekajangan Pekalongan; 2013.

12. Wickramasinghe SC. Lactation management centres: A step forward in successful breast feeding. Sri Lanka J Child Heal [Internet]. 2012 Jun 11;41(2):82-90. Available from: http://www. sljol.info/index.php/SLJCH/article/view/4397.

13. Endah SN, Masdinarsah I. Pengaruh Pijat Oksitosin Terhadap Produksi Kolostrum pada Ibu Post Partum di Ruang kebidanan RS Muhammadiyah Bandung Tahun 2011. J Kesehat Kartika [Internet]. :1-9. Available from: http://www.stikesayani.ac.id/publikasi/e-journal/ filesx/2011/201112/201112-001.pdf.

14. Yuliantika D. Manfaat Pijat Oksitosin Terhadap Pengeluaran Asi Berdasarkan Telaah Literatur. Poltekkes Kemenkes Bandung; 2012.

15. Departemen Kesehatan RI. Panduan Manajemen Laktasi. Jakarta; 2007.

16. Wulandari E. Tingkat Pengetahuan lbu tentang Bendungan ASI di RB An-Nuur Sumber Surakarta. STIKES Husada; 2012.
17. Ummah F. Pijat Oksitosin untuk Mempercepat Pengeluaran ASI pada Ibu Pasca Salin Normal di Dusun Sono Desa Ketanen Kecamatan Panceng Gresik. J Surya. 2014;2(18):121-5.

18. Sujiatini, Nurjanah, Kurniati A. Asuhan ibu Nifas. Yogyakarta: Cyrillus Publisher; 2010.

19. Amahorseja ML, Masni, Bahar. Faktor Determinan Kelangsungan Produksi ASI di Rumah Sakit Umum Daerah Dr. M. Haulussy Ambon. Universitas Hasanudin Ambon; 2012.

20. Desmawati. Penentu Kecepatan Pengeluaran ASI Setelah Sectio Caesaria. Kesmas Public Heal J. 2013;7(8):360-4.

21. Kristianasari W. ASI, Menyusui dan Sadari. Yogyakarta: Nuha Medika; 2009.

22. Paath EF. Gizi Dalam Kesehatan Reproduksi. Jakarta: EGC; 2004.

23. Mardiyaningsih E, Sabri L, Setyowati S. Efektifitas Kombinasi Teknik Marmet dan Pijat Oksitosin terhadap Produksi ASI Ibu Post SC di RS Wilayah Jawa Tengah. J Keperawatan Soedirman [Internet]. 2011;6(1):31-8. Available from: http:// jos.unsoed.ac.id/index.php/keperawatan/article/ view/317/157

24. Rusdiarti. Pengaruh PijatOksitosin pada lbu Nifas Terhadap Pengeluaran ASI di Kabupaten Jember. Akademi Kebidanan Jember; 2009.

25. Haryani S. Hubungan Perawatan Payudara Masa Antenatal dengan Kecepatan Sekresi ASI Postpartum Primipara di Klinik Adinda Karangsari Medan Tahun 2013. Universitas Sumatera Utara; 2013.

26. Sourila D, Alikari V, Prezerakos P, Tsironi M, Zyga S. Frequency of Breastfeeding in Postpartum Women And Related Factors. Arch Hell Med [Internet]. 2015;32(4):484-91. Available from: http://www.mednet.gr/archives/2015-4/pdf/484. pdf.

27. Nasihah M, Mahaijiran D. Hubungan antara Paritas dengan Pemberian Kolostrum pada ibu post partum. J Midpro. 2010;2(2). 